\title{
Correlation of alpine vegetation degradation and soil nutrient status of permafrost in the source regions of the Yangtze River, China
}

\author{
Yibo Wang • Qingbai Wu $\cdot$ Liming Tian • \\ Fujun Niu $\cdot$ Long Tan
}

Received: 21 December 2010/Accepted: 18 January 2012/Published online: 9 February 2012

(C) The Author(s) 2012. This article is published with open access at Springerlink.com

\begin{abstract}
The impacts of alpine vegetation degradation on the main soil nutrients in the permafrost were studied by the comparative analysis of typical plots in the source regions of the Yangtze River. It is found that vegetation degradation has a severe effect on the content of the main soil nutrients, especially in the topsoil $(0-10 \mathrm{~cm})$ where the soil nutrients content were changed. There are good correlations between soil organic matter (SOM) and total nitrogen $(\mathrm{TN})$, total phosphorus (TP) and total potassium (TK) in alpine soil. The change to soil nutrients increases concomitantly with the increasing intensity of vegetation degradation. Soil nutrients change dramatically in the thermokarst lakes in the surrounding area where vegetation is severely degraded. The ratio of SOM, TN, TP and TK in different soil layers of the adjacent thermokarst lakes is $5.88,5.14,3.86$ and 4.43 , respectively. The vegetation degradation accelerates the degradation of alpine soil environment in alpine frozen soil.
\end{abstract}

Keywords Yangtze River - Permafrost .

Alpine vegetation $\cdot$ Soil nutrients

Y. Wang $(\bowtie) \cdot$ L. Tian $\cdot$ L. Tan

Key Laboratory of Western China's Environmental Systems (Ministry of Education), Research School of Arid Environment \& Climate Change, Lanzhou University, 222 South Tianshui Road, 730000 Lanzhou, China

e-mail: yibo_wang@163.com

Y. Wang $\cdot$ Q. Wu $\cdot$ F. Niu

State Key Laboratory of Frozen Soil Engineering,

Cold and Arid Regions Environmental and Engineering

Research Institute, Chinese Academy of Sciences (CAS),

320 West Donggang Road, 730000 Lanzhou, China

\section{Introduction}

The Qinghai-Tibet Plateau, the largest geomorphologic unit on the Eurasian continent, is an important part of the global terrestrial ecosystem, and the largest low-latitude permafrost region in the world. Beside its sensitivity to global climate change, the region plays an active role in moderating such changes at an Asian and even at global level (Cheng et al. 1997). The widely distributed alpine meadows, alpine steppes and alpine swamp meadows that cover most of the area of the Qinghai-Tibet Plateau are the naturally occurring vegetation ecotone and are representative of much of the land area in the Eurasian continent (Li and Zhou 1998). Being located in the interior of the Qinghai-Tibet Plateau, widespread permafrost exists naturally in the headwater regions of the Yangtze River and the Yellow River.

The distribution and variation of permafrost is a major environmental element in the Qinghai-Tibet Plateau, and has a significant effect on the regional vegetation community, and the wetland ecology development and distribution (Wang et al. 2001). According to a recent report by the World Wide Fund for Nature (WWF), the QinghaiTibet Plateau will become $3.8^{\circ} \mathrm{C}$ warmer by the end of the twenty-first century and this will cause permafrost degradation. As a result, the active layers will deepen with the increased groundwater infiltration; thus, the roots of native vegetation will not be able to reach the new aquifer and this area will suffer from drought, causing grassland degradation (WWF 2008).

Either the degradation of soil or the reconstruction of degenerated land will cause a tremendous change in the original ecosystem. These processes will change the biomass productivity rates of soil organic matter (SOM) accumulation and decomposition, which will in turn affect 
the carbon and nitrogen cycle and soil carbon storage in the ecosystem (Lal et al. 1995). From the perspective of global change, carbon sequestration and release in the Plateau soils are more sensitive to global change; thus, they play an important role in the carbon balance of the regional ecosystem (Wang et al. 2007). Based on a GIS study, the alpine grassland in northern Tibet which has degraded in recent years accounts for half of the entire grassland region in 2004 (Gao et al. 2010). In another study, the daily wind erosion rate increased sharply with the increase of the rate of grassland degradation ( $\mathrm{Li}$ et al. 2005).

At present, the degradation of grassland in the QinghaiTibet Plateau is serious. According to an early study by $\mathrm{Ma}$ et al. (1999a, b), the degraded grassland has an approximate area of $0.45 \times 10^{8} \mathrm{~km}^{2}$, which is one-third of the total area of Qinghai-Tibet Plateau. The most seriously degraded area is the secondary bare land-_black beach", accounting for $16.5 \%$ of the total area of degraded grassland. Grassland degradation has threatened the local ecosystem, biodiversity conservation and economic development of livestock (Li and Zhou 1998; Zhou et al. 2003, 2005). Essentially, the degradation of grassland means the degradation of the Vegetation-Soil system (Chen and Wang 2000).

Soil nutrients including soil organic carbon (SOC), N, P and $\mathrm{S}$ are important plant nutrients which participate in almost all ecosystem processes (Harrison 1985; Juan and Romon 1997). Many studies have shown that soil nutrients such as SOC, N and P would decrease with the increased tillage and soil depth (Urioste et al. 2006). Soil active organic carbon (SAOC) content decreases with the increase of soil depth in different types of land use. The allocation ratio of SAOC decreases with the increase of soil depth, while the allocation ratio of dissolved organic carbon (DOC) increases with the increase of soil depth (Yu et al. 2007). Tillage leads to the rapid decrease of light fraction organic carbon (LFOC) (Zhao et al. 2006). Overall, returning crop residues along with zero tillage improved the aggregation of SOC and nitrogen, while burning in combination with conventional tillage resulted in the deterioration of these soil properties. According to the study, SOC storage in the Qinghai-Tibet Plateau accounted for 2.6 or $2.4 \%$ of the world SOC pool $(1,500 \mathrm{Gt}$ ) (Fang et al. 1996; Wang et al. 2002; Tao et al. 2006). Grassland SOC content across the entire Qinghai-Tibet Plateau totals about $33.5 \mathrm{Pg}$, of which $12.3 \mathrm{Pg}(37 \%)$ is stored in the permafrost region (Wang et al. 2002; Luo et al. 2000).

At the same time, a large number of studies have shown that permafrost is gradually being degraded, presumably due to global warming. Thawing permafrost creates thermokarst terrain-uneven surface topography including pits, troughs, mounds and depressions, which can fill with water. Ponding of water in depressions creates thermokarst lakes, which may expand as a result of both thermal and mechanical erosion over time with scales of decades to centuries (Czudek and Demek 1970).

Thermokarst lakes are common features of ice-rich permafrost landscapes. Thermokarst damages agricultural fields and ecosystems such as forests by drying in mounded areas and flooding in low-lying zones. Furthermore, it can contribute to erosion and increase sedimentation and siltation of rivers, which poses additional environmental concerns. Numerical simulation in typical thermokarst lakes in Alaska has shown that the evolution of thermokarst lakes and climate change are closely related, which induces the variation of permafrost in the adjacent thermokarst lakes (Ling and Zhang 2003). The thermokarst process has a significant impact on the ecological environment in permafrost, and it also accelerates the organic decomposition process which can release soluble substances in permafrost, thus affecting the chemical properties of soil mass and surface runoff (Truett and Kertell 1992; Kokelj and Lewkowicz 1999; Kokelj et al. 2002). A previous study showed that $\mathrm{CH}_{4}$ bubbling from newly forming thermokarst lakes comprised $33-87 \%$ of the high-latitude increase in atmospheric methane concentration (Walter et al. 2007). There are signs that the formation of thermokarst lakes can affect SOM in frozen soil.

Currently, research on the response of soil nutrients to the degraded grassland in the Qinghai-Tibet Plateau as well as on the change to soil nutrients in regional vegetation caused by thermokarst lakes is scarce. Therefore, it is crucial to understand the nutrient cycling in permafrostaffected soils in the Plateau in order to evaluate the biogeochemical response to global climate change objectively.

Consequently, the objectives of this study aim to: (1) analyze the response of soil nutrients to grassland degradation in the permafrost region of the Qinghai-Tibet Plateau; (2) compare the differences between the changes to soil nutrients caused by thermokarst lakes and natural degradation conditions.

\section{Material and methods}

The study area description

The study area is in the source region of the Yangtze River which is in the centre of the Qinghai-Tibet Plateau, located between $32^{\circ} 30^{\prime}-35^{\circ} 40^{\prime} \mathrm{N}$ and $90^{\circ} 30^{\prime}-95^{\circ} 35^{\prime} \mathrm{E}$, with an area of $1.212 \times 10^{5} \mathrm{~km}^{2}$. The mean elevation of the area ranges from 4,315 to $5,126 \mathrm{~m}$ (Wang et al. 2001, 2008; Yao 2002). The area is dominated by a typical continental alpine climate with mean annual air temperature (MAAT) ranging from -3 to $-7^{\circ} \mathrm{C}$ which depends on the elevation and the thickness of frozen soil. The mean annual precipitation (MAP) ranges from 150 to $540 \mathrm{~mm}$ and centers on 
the period from June to August, more in the form of summer storms and less in snow. The annual evaporation is 1,204-1,327 mm, which far exceeds the MAP; thus, the aridity index is high (8-20). The freeze period is up to 7-8 months per year, from September to April. Soil type in the study area is classified according to the Chinese soil taxonomy (NSSO 1998). The major types of soil are alpine meadow soil, alpine steppe meadow soil, alpine swamp meadow soil and alpine grassland soil. Soil develops slowly in highly cold environments with high altitude and hypoxia, and the soil genetic horizons are generally thin and fragile; thus, it is difficult to recover if the soil is degraded (Li and Zhou 1998; Wang et al. 2001, 2008; Li et al. 2010). Soil degradation is serious in the study area, and soil erosion is one of the main causes of soil degradation (Wang et al. 2008). The main types of erosion are divided into freeze-thaw erosion, wind erosion and water erosion ( $\mathrm{Li}$ et al. 2009). There are different sizes of thermokarst lakes occurring as a result of permafrost degradation in the studied area; some are perennial waterlogged, some are seasonal waterlogged. Severe vegetation degradation occurs around the thermokarst lakes; in some parts, the mineral soil is completely exposed.

The types of vegetation community in the studied area mainly consist of two categories: alpine cold meadow and alpine cold swamp meadow, and the dominant species include Kobresia pygmaea, K. humilis, K. capillifolia, $K$. tibetica, Stipa aliena, Festuca ovina, Poa апnиa, Elymus nutans, Ptilagrostis dichotoma, Carex atrofusca, Leontopodium leontopodioides.

\section{Soil sampling and treatments}

According to vegetation ecology and the degree of degradation, the study area is classified into different types, and three to five sampling transects in each study area at Fenghuo Mountain in the source region of the Yangtze River are selected. The actual sample size of the sampling transects is $10 \times 10 \mathrm{~m}$ in width separated by a distance of $3-5 \mathrm{~m}$, and then took samples at three depths $(0-10$, $10-20,20-30 \mathrm{~cm})$ from each transect. Firstly, three replicate samples were taken using the $100 \mathrm{ml}$ metal ring at each transect, and stored them in aluminum boxes. Afterward, the soil moisture content and bulk density were determined by oven drying the samples at $105^{\circ} \mathrm{C}$ on average. At the same time, approximately $1 \mathrm{~kg}$ of soil samples in sealed plastic bags was transported to the laboratory, for further physical and chemical analysis. In areas where the soil thickness was only about $10 \mathrm{~cm}$ and there was only sand and gravel below this depth, only sampled two layers as the soil depth was insufficient for three samples. (Note: The data were collected in July 2007 and August 2008).
Analytical methods

The soil chemical analyses include SOM, total nitrogen (TN), total phosphorus (TP) and total potassium (TK) in the soil. SOM was measured using the Potassium Bichromate Titrimetric Method (Ji 2005). The TN was measured using the Semi-Micro Macro Kjeldahl Method (Ma et al. 1999a, b). The TP was measured with the $\mathrm{HClO}_{4}-\mathrm{H}_{2} \mathrm{SO}_{4}$ Method (Zhou 1996) and the TK was measured with $\mathrm{NaOH}$ fusion-flame spectrometry. For the measurement of SOM, $\mathrm{TN}, \mathrm{TP}$ and TK determination, three replications were taken from each soil layer.

Data analysis

SPSS13.0 and other geostatistic methods were used to analyze the correlation of experimental data.

\section{Results and discussion}

Correlation among soil nutrients and soil moisture content

Soil nutrients are the key factors of stable soil environment in permafrost, and the relationship among soil nutrients is one of the main indicators of soil environment. It can be seen from Table 1 that the correlation between SOM and $\mathrm{TN}$ is the strongest in the soil depth between 0 and $10 \mathrm{~cm}$ ( $r=0.9876, \quad P \leq 0.05)$, followed by the correlation between TP and TK $(r=0.8138, P \leq 0.05)$. The correlation between the other components is not significant. The results show that the variations of SOM and TN, TP and TK are most closely related to the soil surface horizons, along with the change of soil environmental effect between each other. Table 1 also shows that the correlation between

Table 1 Correlation coefficient for relationships among soil nutrients

\begin{tabular}{llllll}
\hline Soil depth $(\mathrm{cm})$ & Item & SOM & TN & TP & TK \\
\hline $0-10$ & SOM & 1 & & & \\
& TN & 0.9876 & 1 & & \\
& TP & 0.1636 & 0.1275 & 1 & \\
& TK & 0.1522 & 0.3763 & 0.8138 & 1 \\
$10-20$ & SOM & 1 & & & \\
& TN & 0.9764 & 1 & & \\
& TP & 0.2822 & 0.2692 & 1 & \\
$20-30$ & TK & 0.2055 & 0.1823 & 0.9257 & 1 \\
& SOM & 1 & & & \\
& TN & 0.9578 & 1 & & \\
& TP & 0.0719 & 0.0437 & 1 & \\
& TK & 0.1816 & 0.1799 & 0.8478 & 1 \\
\hline
\end{tabular}


TK and TN is poor $(r=0.3763, P \leq 0.05)$ and even weaker between SOM and TP, TK. The above analysis illustrates that the interdependence among other components of soil nutrients is poor, apart from between SOM and TN, TP and TK in the topsoil of the permafrost region in an alpine cold environment.

At the depth of 10-20 cm, the correlation between SOM and TN is still the strongest $(r=0.9764, P \leq 0.01)$, followed by TP and TK $(r=0.9257, P \leq 0.05)$; TK and TN is insignificantly correlated $(r=0.1799, P \leq 0.05)$. In addition, correlation between other components and the surface is essentially the same; the correlation coefficient changes very slightly. In the second layer, the correlation coefficient between SOM and TN is slightly lower, but still a strong correlation occurs $(r=0.9764, P \leq 0.01)$; the correlation between TP and TK is stronger, and its correlation coefficient increases by $13.8 \%$.

At the depth of 20-30 cm, the correlation between SOM and TN is still the strongest $(r=0.9578, P \leq 0.01)$; the correlation between TP and TK is still evident $(r=0.8478$, $P \leq 0.05)$. The correlation coefficient between TK and TN is lower $(P \leq 0.05)$, but the correlation between SOM and TP, TK decreases by 11.6 and $74.5 \%$, respectively. On one hand, the soil nutrients content of permafrost-affected soils reduces at the depth of 20-30 cm; on the other hand, some nutrients content would vary with the decrease of vegetation roots below $20 \mathrm{~cm}$.

Overall, the correlation between SOM and TN changes slightly with the variation of soil depths, and the correlation coefficient ranges between 0.9578 and $0.9876(P \leq 0.05)$. The result shows that SOM and TN are closely related in the soils of the source region of the Yangtze River, because most nitrogen is tied with the biomass, and this result is consistent with Wang et al. (2005) who found that the correlation coefficient between SOM and $\mathrm{TN}$ is 0.9786 $(P \leq 0.05)$, and that meadow degradation is due to human activity, climate warming and permafrost degradation in the Qinghai-Tibet Plateau's permafrost region. The correlation between TP and TK increases at first and then decreases, and it reaches its peak in the second layer $(r=0.9275$, $P \leq 0.05)$; despite this, the general trend is still rising. The weathering process of phosphorus and potassium of soil is identical in the permafrost region of the source regions of the Yangtze River, both phosphorus and potassium are from the identical soil parent materials, and then convert to available phosphorus and potassium after long-term physical, chemical and biological weathering. Furthermore, the utilization of phosphorus and potassium for alpine vegetation is consistent. This distinctive correlation shows the particularity of the frozen soil environment.

Soil moisture has great importance with respect to total nutrient masses and their redistribution in the profile. Figure 1 shows that the moisture content in the upper

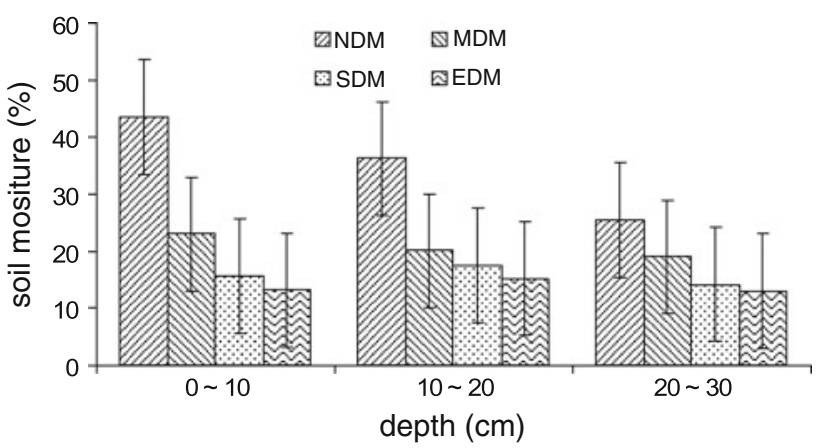

Fig. 1 Variation of soil moisture content in topsoil $(0-30 \mathrm{~cm})$ of alpine meadow

$30 \mathrm{~cm}$ layer of alpine meadow soil showed a strong regularity with changes in the whole profile. With the increase of soil depth, the soil moisture content decreased quickly, particularly below $20 \mathrm{~cm}$ in depth. Soil moisture content in the alpine steppe can be affected by a number of factors such as local precipitation, terrain conditions and soil texture, and its spatial distribution is irregular. Waterstorage capacity in topsoil layers is of great importance to the growth of vegetation. Dense root systems and high evapotranspiration of alpine meadow vegetation require a large water supply in the root areas (Zhou 2001). With the degradation of such meadows and the concomitant reduction in MDM, SDM and EDM, the water-storage capacity of topsoil layers decreases as well. With the increase of the soil depth from $0-10$ to $20-30 \mathrm{~cm}$, mean moisture content decreases by $41,17,10$ and $2 \%$ in NDM, MDM, SDM and EDM accordingly. It shows that the moisture content in topsoil layers of severely or extremely degraded alpine meadow tends to be similar.

Relationships between vegetation coverage and soil nutrients

Vegetation degradation is one of the primary causes of soil degradation in the alpine cold meadow of the Qinghai-Tibet Plateau, and soil degradation is bound to bring further degradation of vegetation (Zhou et al. 2005). However, soil degradation inevitably leads to changes in the soil nutrients content. A great number of studies indicate that there is a certain relationship between vegetation coverage and soil nutrients, but the relationship is not always invariable under different conditions. Wang et al. (2008) found that there is a high correlation between LFOC in SOM and vegetation coverage in the alpine meadow and alpine steppe, and that the relationships between total soil organic carbon (TOC) and its vegetation coverage are weak.

At the depth of $0-10 \mathrm{~cm}$ in the topsoil, there exists a very good correlation between vegetation coverage and different soil nutrients, particularly the SOM and TN. The 
relationships between vegetation coverage and content of TP and TK are also strong (Fig. 2a). At the depth of $10-20 \mathrm{~cm}$, there is still a strong correlation even though the relationships between vegetation coverage and SOM and $\mathrm{TN}$ increase slightly while the relationships between vegetation coverage and TP and TK decrease slightly (Fig. 2b). The correlation coefficients of each component in Fig. $2 c$ are greatly reduced, which indicate that the variation of surface vegetation has little direct impact on soil nutrients in the $20-30 \mathrm{~cm}$ band and below. This differs with the findings of Alison et al. (1999) who found that the correlation coefficient between vegetation coverage and soil nutrients including TN, TP and TK is respectively $-0.03,-0.39$ and 0.41 on an uninfluenced area in Igloolik
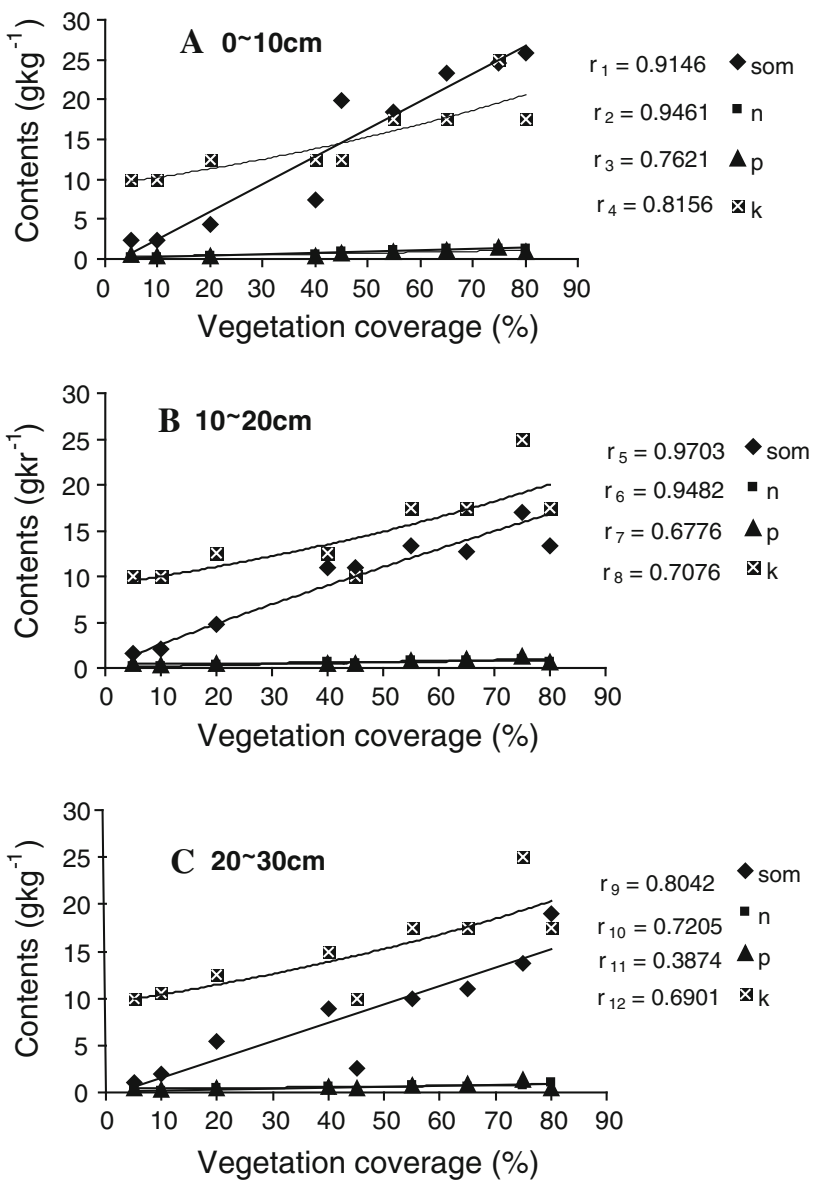

Fig. 2 Relationships between vegetation coverage and SOM, TN, TP and TK of the $0-10 \mathrm{~cm} \mathrm{(a),} 10-20 \mathrm{~cm}(\mathbf{b})$ and $20-30 \mathrm{~cm}$ (c) layers of alpine cold meadow soils in the study area. $r_{1}, r_{5}$ and $r_{9}$ are correlation coefficients for relationship between SOM and vegetation coverage in 0-10, 10-20 and 20-30 cm, respectively. $r_{2}, r_{6}$ and $r_{10}$ are correlation coefficients for relationship between $\mathrm{TN}$ and vegetation coverage in $0-10,10-20$ and $20-30 \mathrm{~cm}$, respectively. $r_{3}, r_{7}$ and $r_{11}$ are correlation coefficients for relationship between TP and vegetation coverage in $0-10,10-20$ and $20-30 \mathrm{~cm}$, respectively. Similarly, $r_{4}, r_{8}$ and $r_{12}$ are correlation coefficients for relationship between TK and vegetation coverage in $0-10,10-20$ and $20-30 \mathrm{~cm}$, respectively
Island, Nunavut. This indicates that the relationship between vegetation and soil is different in middle-latitude and high-latitude alpine cold circumstance.

Generally, the relationships between vegetation coverage and soil nutrients are weaker with the increase of depth, but there is no evident abrupt decrease in the $0-20 \mathrm{~cm}$ layer. Because the vegetation of grassland assigns the photosynthetic products to roots, the live roots, dead roots and coarse organic matter in the alpine region are concentrated in the 0-20 cm layer (Wang et al. 1998). Each correlation coefficient decreased abruptly in the $20-30 \mathrm{~cm}$ layer, which is mainly due to the low temperature in alpine region. The formation process of soil requires a long time; in an area where there is little annual precipitation, the organic matter of topsoil transported to the deep soil is little, the relative humidity of soil is comparatively large and the supply of deep nutrients is restricted. At the same time, owing to the relatively undersized alpine vegetation, the distribution of roots is shallow and the soil at a deeper level seldom gets material supply. The relationships between vegetation and SOM and TN are consistently strong in the entire transect at a depth between 0 and $30 \mathrm{~cm}$; this demonstrates that surface vegetation is closely related to the content of SOM and $\mathrm{TN}$, and demonstrates that SOM and TN of soil are major factors of alpine vegetation's growth and development.

Relationships between vegetation degradation and the variation of soil composition

Based on the degradation of the alpine meadow in the study area, we divided the meadow degradation into five levels: non-degraded alpine meadow (i.e., native vegetation), lightly degraded alpine meadow, moderately degraded alpine meadow, severely degraded alpine meadow and extremely degraded alpine meadow (Ma et al. 2002). Soil nutrients content and distribution pattern of meadow with different degradation in the vertical profile are different.

As shown in Table 2, in soil at a depth between 0 and $30 \mathrm{~cm}$, SOM content decreases with the severity of alpine meadow degradation. The total profile SOM content of the non-degraded alpine meadow is $48.7 \mathrm{~g} / \mathrm{kg}$ at its highest. SOM at the depth of $0-10 \mathrm{~cm}$ of NDM was up to six times greater than that in more degraded areas. In the same profile, SOM content significantly increases with depth reduction, while the SOM content in the same layer decreases with the intensification of the degradation. The SOM content in the soil depth between 0 and $10 \mathrm{~cm}$ is significantly higher than that in soil depth between 10-20 and $20-30 \mathrm{~cm}$. In an alpine meadow under different degradation, the SOM content in the $0-10 \mathrm{~cm}$ level accounts for $43 \%$ of that in the soil depth between 0 and $30 \mathrm{~cm}$ and accounts for $74 \%$ of that in the soil depth between 0 and 
Table 2 Soil nutrients differ from soil layer at different degraded alpine meadows $(\mathrm{g} / \mathrm{kg})$

\begin{tabular}{llrrrrr}
\hline $\begin{array}{l}\text { Soil } \\
\text { nutrients }\end{array}$ & $\begin{array}{l}\text { Soil depth } \\
(\mathrm{cm})\end{array}$ & NDM & LDM & MDM & SDM & EDM \\
\hline SOM & $0-10$ & 17.3 & 20.9 & 13.7 & 4.3 & 2.3 \\
& $10-20$ & 15.1 & 13.0 & 10.9 & 4.8 & 1.8 \\
& $20-30$ & 16.3 & 10.4 & 5.7 & 5.4 & 1.5 \\
& $0-30$ & 48.7 & 44.3 & 30.3 & 14.5 & 5.6 \\
TN & $0-10$ & 1.3 & 1.2 & 0.7 & 0.3 & 0.2 \\
& $10-20$ & 0.8 & 0.7 & 0.5 & 0.3 & 0.2 \\
& $20-30$ & 0.9 & 0.7 & 0.4 & 0.4 & 0.1 \\
& $0-30$ & 3.0 & 2.5 & 1.5 & 1.0 & 0.5 \\
TP & $0-10$ & 1.1 & 0.9 & 0.6 & 0.4 & 0.5 \\
& $10-20$ & 1.0 & 0.8 & 0.5 & 0.5 & 0.4 \\
& $20-30$ & 0.9 & 0.8 & 0.5 & 0.5 & 0.4 \\
& $0-30$ & 3.0 & 2.5 & 1.6 & 1.4 & 1.3 \\
TK & $0-10$ & 21.4 & 17.7 & 12.3 & 12.1 & 10.4 \\
& $10-20$ & 21.2 & 17.5 & 12.0 & 12.5 & 10.0 \\
& $20-30$ & 21.1 & 17.3 & 11.7 & 12.9 & 9.6 \\
& $0-30$ & 63.7 & 52.5 & 36.0 & 37.5 & 30.0 \\
\hline
\end{tabular}

The data in the table are shown by average values, but the value in $0-30 \mathrm{~cm}$ is the sum of $0-10,10-20$ and $20-30 \mathrm{~cm}$

$N D M$ non-degraded meadow, $L D M$ lightly degraded meadow, $M D M$ moderately degraded meadow, $S D M$ severely degraded meadow, $E D M$ extremely degraded meadow

$20 \mathrm{~cm}$. This trend in general agrees with that of Wang et al. (1998).

In the soil profile $(0-30 \mathrm{~cm}), \mathrm{TN}$ content decreases with the severity of alpine meadow degradation. The TN content value in the non-degraded alpine meadow is $1.3 \mathrm{~g} / \mathrm{kg}$ at its highest, which is 1.1, 1.9, 4.3 and 6.5 times greater than the value of the lightly, moderately, severely and extremely degraded alpine meadows, respectively. It shows a similar but slower trend in the SOM content. A large amount of the TN content enriches in the topsoil. In each profile, the TN content in the surface accounts for more than $40 \%$ of the entire profile which is closely related to the SOM distribution. This shows that the TN in alpine soils is tied to the SOM due to the pattern of SOM accumulation and nutrient cycling.

In the soil profile $(0-30 \mathrm{~cm}), \mathrm{TP}$ content decreases with the severity of alpine meadow degradation and gradually becomes stabilized. The non-degraded alpine meadow has a highest TP content value of $1.1 \mathrm{~g} / \mathrm{kg}$, which is respectively 1.2, 1.8, 2.8 and 2.2 times greater than the value of the lightly, moderately, severely and extremely degraded alpine meadows. Such a trend can be interpreted as the result of erosion.

In the soil profile $(0-30 \mathrm{~cm})$, TK content is higher than SOM, TN and TP. TK content decreases with the severity of alpine meadow degradation. The highest TK content value in the non-degraded alpine meadow is $63.7 \mathrm{~g} / \mathrm{kg}$, which is respectively 1.2, 1.8, 1.7 and 2.1 times greater than the values of the lightly, moderately, severely and extremely degraded alpine meadows. In the same profile which has the same vegetation characteristics, TK content does not change significantly with depth. This indicates that TK is the major soil nutrient least affected by degradation.

The nutrients content of soil decreases with the severity of alpine meadow degradation as follows: SOM (10.06) $>$ $\mathrm{TN}(6.27)>\mathrm{TP}(2.36)>\mathrm{TK}$ (2.22) (lower intensity: in the soil at a depth of $0-30 \mathrm{~cm}$, the ratio between non-degraded alpine meadow soil nutrient content and extremely degraded alpine meadow soil nutrients content). It indicates that the SOM is very sensitive to the degradation in alpine meadow. Due to the cold environment in the studied area, SOM decomposes slowly at a low temperature, which results in a net accumulation. Global warming and human activities influence the degradation of permafrost and lead to changes in soil nutrients. The soil nutrients content decreases with the degradation of grassland, which indicates that the vegetation and the soil nutrient content have a close relationship and mutual feedback.

\section{Thermokarst lake and the soil nutrients}

The permafrost region of the Qinghai-Tibet Plateau is very sensitive to global change. Under the global warming conditions, permafrost degradation occurs. Some of the melted water flows along the surface, gathers in the hollows and forms thermokarst lakes and these thermokarst lakes affect the surrounding environment strongly.

According to a comparison between soil nutrients of the adjacent thermokarst lakes and the extremely degraded alpine meadow, we find that the levels of soil nutrients in the proximate thermokarst lakes are higher than those in the extremely degraded alpine meadow at the same depth (Fig. 3). The reason for this may be that the surrounding vegetation of the thermokarst lakes was seriously degraded, and the soil nutrients accumulate from the runoff. At the same time, the first layer suffered from heavy erosion resulting in loss of soil nutrients. The factor that affects soil nutrients of the third layer is mainly freeze-thaw erosion. Due to freeze-thaw erosion and leaching, the near-surface soil is subjected to the loosening affected by the freezethaw cycles. Ice segregation leads to heaving during the freezing process. Erodibility of soil increases in the winter, along with the soil moisture profile filling and the surface structure breaking down with freezing and thawing. The deposition occurs because of upwards water loss, similar to a caliche layer. Besides, the formation of the deposition is excluded from the ice lenses during the winter; nutrients gather in the deep layer and are deposited in the second 
Fig. 3 Comparison of different soil nutrients between thermokarst lakes and extremely degraded meadow. TKL thermokarst lakes, $E D M$ extremely degraded meadow. The data in the figure are showed by average values
A

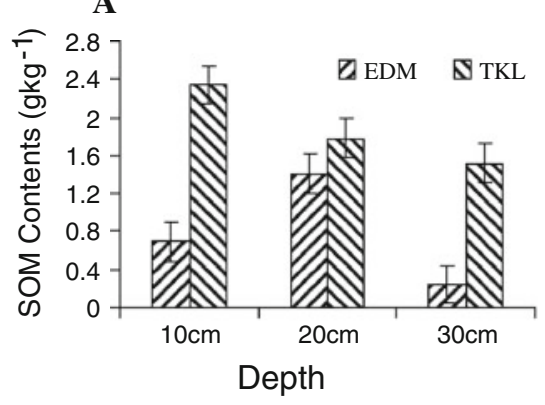

C

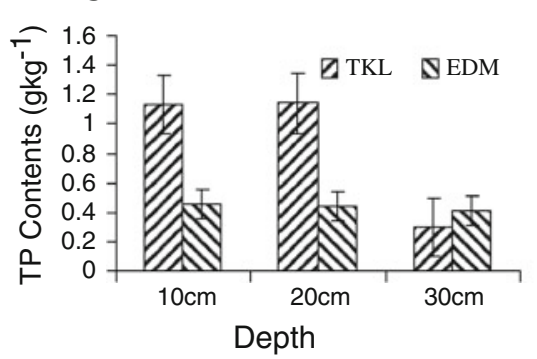

\section{B}

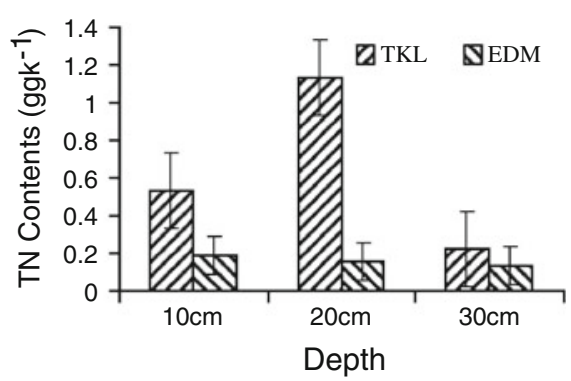

D

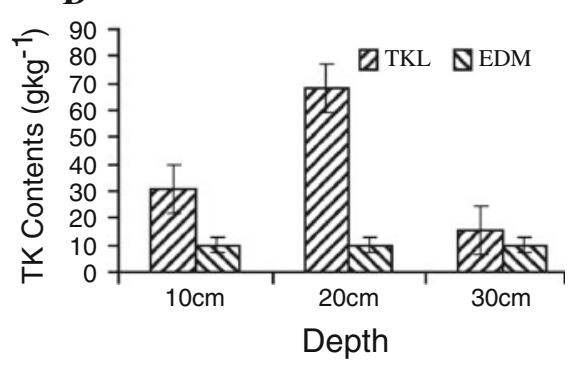

layer. Thus, the soil nutrients appear to gather in the second layer. The changes ratio of SOM, TN, TP and TK in different soil layers of the thermokarst lakes is 5.88, 5.14, 3.86 and 4.43 , respectively. Under natural conditions, the variation of SOM, TN, TP and TK is respectively 1.54, 1.46, 1.10 and 1.0 in the extremely degraded area. The surrounding thermokarst lakes have higher soil nutrients degradation rates than those occurring under natural condition.

As shown in Fig. 3, in the $0-30 \mathrm{~cm}$ soil layer, the SOM content of the adjacent thermokarst lakes is much less than that of the extremely degraded alpine meadow, while other soil nutrients (TN, TP, TK) are much higher than extremely degraded alpine meadow. The ratios are $0.41,3.93,1.97$ and 3.81. This shows that the formation and development of the thermokarst lakes can influence alpine soil environment and it is a more serious threat than that of the natural degradation in the stability and security of the permafrost environment.

\section{Conclusions}

1. The soil nutrients content and distribution in the profile of the alpine meadow in the source region of the Yangtze River are affected by the degradation of vegetation. In the $0-30 \mathrm{~cm}$ soil layer, the SOM and TN have the strongest correlation $(r=0.97)$; the TP and TK correlation coefficient in soil is higher than 0.8 ; other components have poor correlation. The major nutrients of the alpine meadow are SOM and TN, other nutrients are relatively lower in content. The SOM and $\mathrm{TN}$ are the main elements that affect the stability of the alpine soil environment.
2. The soil nutrients content decreases with the severity of alpine meadow degradation. The intensity reduction order is: $\mathrm{SOM}>\mathrm{TN}>\mathrm{TP}>\mathrm{TK}$. Besides TK, soil nutrients content decreases with the soil depth in the same profile. Soil nutrients content at the same depth decreases with the severity of alpine meadow degradation. This indicates that in alpine regions of the Yangtze River, changes in soil environment and vegetation characteristics have a strong correlation. These two factors are interdependent and form a mutual influence control mechanism. Climate change and human activity have a serious impact on climate in this fragile alpine ecological environment.

3. Thermokarst lake is a special phenomenon of the degraded permafrost in the source regions of the Yangtze River. The formation of thermokarst lakes has severe influence on soil environment of alpine meadow. The SOM content in affected zone of thermokarst lake is less than the EDM, while other soil nutrients content (TN, TP, TK) are much more than EDM and less than MDM. Compared to the degradation of natural vegetation's impact on the soil environment, impact of thermokarst lake is quicker and more dramatic, it has also localized damage effect on soil environment of alpine meadow, and can induce rapid damage to soil environment.

Alpine meadow is one of the main ecological types in the source regions of the Yangtze River and studies on alpine meadow soil, vegetation and hydrological characteristics are of great practical significance. It is beneficial to understand deeply the alpine ecological environment in permafrost of the Qinghai-Tibet Plateau, and it is 
conducive to the formulation and implementation of developmental, constructive and protective measures in the source regions of the Yangtze River.

Acknowledgments The project was supported by the State Key Program of National Natural Science of China (Grant No. 41030741); the grant of the Important Knowledge Innovation Program of the CAS (No. KZCX2-YW-Q03-04); this study was funded by the National Key scientific Plan (973) (No. 2010CB434813); and the State Key Laboratory of Frozen Soil Engineering (SKLFSE200804). Professor Chienlu Ping in Alaska University and Emily Derbyshire are appreciated for their assistance with editing of the paper and with the English.

Open Access This article is distributed under the terms of the Creative Commons Attribution License which permits any use, distribution, and reproduction in any medium, provided the original author(s) and the source are credited.

\section{References}

Alison MD, Peter GK, Susan DMR (1999) Soil nutrients and vegetation characteristics of a Dorset/Thule site in the Canadian Arctic. Arctic 52:204-213

Chen ZZ, Wang SP (2000) Typical steppe ecosystem in China. Science Press, Beijing, pp 15-20

Cheng GD, Li PJ, Zhang XS (1997) Assessment about effects of climatic change on accumulated snow, glacier and frozen soil. Gansu Culture Press, Lanzhou

Czudek T, Demek J (1970) Thermokarst in Siberia and its influence on the development of lowland relief. Quat Res 1:103-120

Fang JY, Liu GH, Xu SL (1996) Carbon pool of terrestrial ecosystem in China. In: Wang GC, Wen YP (eds) Monitoring of greenhouse gas concentration and emission and relevant processes. China Environmental Science Press, Beijing, pp 109-128

Gao QZ, Wan YF, Xu HM, Li Y, Wz JC, Borjigidai A (2010) Alpine grassland degradation index and its response to recent climate variability in northern Tibet, China. Quat Int 226:143-150

Harrison AF (1985) Effects of environment and management on phosphorus cycling in terrestrial ecosystems. J Environ Manag 20:163-179

Ji TW (2005) Comparison on determining the organic matter contents in the soils by different heating methods in the Potassium Dichromate Volumetric Method. Acta Agriculturae Zhejiangensis 17(5):311-313

Juan AG, Romon AR (1997) Organic fractions, N, P and S changes in a semiarid haplustoll under different crop sequences. Soil Tillage Res 42:221-228

Kokelj SV, Lewkowicz AG (1999) Stalinization of permafrost terrain due to national geomorphic disturbance, Fosheim Peninsula, Ellesmere Island. Arctic 52:372-385

Kokelj SV, Smith CAS, Brun CR (2002) Physical and chemical characteristics of the active layer and permafrost, Herschel Island, western Arctic Coast, Canada. Permafrost Periglac Process 13(2): 171-185

Lal R, Fausey NR, Eckert DJ (1995) Land use and soil management effects on emissions of radiatively active gases from two soils in Ohio. In: Lal R, Kimble J, Levine E, Stewart BA (eds) Soil management and greenhouse effect. CRC Press, Boca Raton, FL, pp 41-59

Li FR, Kang LF, Zhang H, Zhao LY, Shirato Y, Taniyama I (2005) Changes in intensity of wind erosion at different stages of degradation development in grasslands of Inner Mongolia, China. J Arid Environ 62:567-585

Li WH, Zhou XM (1998) Ecosystems of Tibetan Plateau and approach for their sustainable management. Guangdong Science \& Technology Press, Guangzhou, pp 41-50

Li YS, Wang GX, Zhao L, Wu QB, Wang YB, Zhang RH (2010) Response of soil moisture in the permafrost active layer to the change of alpine meadow coverage on the Tibetan Plateau. J Glaciol Geocryol 32(1):157-165

Li YS, Zhang RH, Wang GX, Zhao L, Ding YJ, Wang YB (2009) Spatial variability characteristics of soil organic carbon and nitrogen reveal typical alpine meadow degradation on QinghaiTibetan Plateau. Environ Sci 30(6):1826-1831

Ling F, Zhang TJ (2003) Numerical simulation of permafrost thermal regime and talik development under shallow thaw lakes on the Alaskan Arctic Coastal Plain. J Geophys Res 108(D16):4511. doi:10.1029/2002JD003014

Luo GB, Zhang GL, Gong ZT (2000) A real evaluation of organic carbon pools in cryic soils of China. In: Lal R, Kimble JM, Stewart BA (eds) Global climate change and coil regions ecosystems. Advance in soil science. Lewis Publishers, Boca Raton, FL, pp 211-222

Ma LY, Zhai MP, Lin P (1999a) Analysis of soil physi-chemical properties of Beijing Xishan mountain. J Beijing For Univ 21(1):32-37

Ma YS, Lang BN, Wang QJ (1999b) Review and prospect of the study on black soil type deteriorated grassland. Pratacultural Sci 16(2):5-9

Ma YS, Lang BN, Li QY, Shi JJ, Dong QM (2002) Study on rehabilitating and rebuilding technologies for degenerated alpine meadow in the Changjiang and Yellow River source region. Pratacultural Sci 19(9):1-5

National Soil Survey Office (NSSO) (1998) Soil of China. China Agriculture Press, Beijing, pp 20-29

Tao T, Shen CD, Gao QZ, Sun YM, Yi WX, Li YN (2006) Soil organic carbon storage and vertical distribution of alpine meadow on the Tibetan Plateau. Acta Geogr Sinica 61(7):720-728

Truett JC, Kertell K (1992) Tundra disturbance and ecosystem production: implications for impact assessment. Environ Manag 16(4):485-494

Urioste AM, Hevia GG, Hepper EN, Anton LE, Bono AA, Beschiazzo DE (2006) Cultivation effects on the distribution of organic carbon, total nitrogen and phosphorus in soils of the semiarid region of Argentinian Pampas. Geoderma 136:621-630

Walter KM, Edwards ME, Grosse G, Zimov SA, Chapin FS III (2007) Thermokarst lakes as a source of atmospheric $\mathrm{CH}_{4}$ during the last deglaciation. Science 318:633-636

Wang GX, Cheng GD, Shen YP (2002) Soil organic carbon pool of grasslands on the Tibetan Plateau and its global implication. J Glaciol Geocryol 24(6):693-700

Wang GX, Li YS, Wang YB, Wu QB (2008) Effects of permafrost thawing on vegetation and soil carbon pool losses on the Qinghai-Tibet Plateau, China. Geoderma 143:143-152

Wang GX, Cheng GD, Shen YP (2001) Research on ecological environmental change in Changjiang-Yellow Rivers source regions and their integrated protection. Lanzhou University Press, Lanzhou, pp 75-96

Wang WY, Wang QJ, Wang G, Jing ZC (2007) Effects of land use degradation and rehabilitation on vegetation carbon and nitrogen content of alpine meadow in China. J Plant Ecol 31(6): 1073-1078

Wang YF, Chen ZZ, Larry TT (1998) Distribution of soil organic carbon in the major grasslands of Xilinguole, Inner Mongolia, China. Acta Phytoecol Sinica 22(6):545-551

Wang CT, Long RJ, Wang QJ, Jing ZC, Shang ZH, Ding LM (2005) Distribution of organic matter nitrogen and phosphorus along an 
altitude gradient and productivity change and their relationships with environmental factors in the alpine meadow. Acta Prataculturae Sinica 14(4):15-20

World Wildlife Fund (WWF) (2008) Impact of climate change and it's eco-hydrological in the source region of Yangtze River. Meteorological Press, Beijing, pp 13-61

Yao TD (2002) Cryospheric changes in the middle part of the Qinghai-Tibet Plateau. Geological Press, Beijing

Yu WT, Ma Q, Zhao X, Zhou H, Li JD (2007) Changes of soil active organic carbon pool under different land use types. Chin J Ecol 26(12):2013-2016

Zhao X, Yu WT, Li JD, Jiang ZS (2006) Research advances in soil organic carbon and its fractions under different management patterns. Chin J Appl Ecol 17(11):2203-2209
Zhou HK, Zhou L, Zhao XQ, Liu W, Yan ZL, Shi Y (2003) Degradation process and integrated treatment of "black soil beach" grassland in the source region of Yangtze and Yellow Rivers. Chin J Ecol 22(5):51-55

Zhou HK, Zhao XQ, Zhou L, Liu W, Li YN, Tang YH (2005) A study on correlations between vegetation degradation and soil degradation in the alpine meadow of the Qinghai-Tibet Plateau. Acta Prataculturae Sinica 14(3):31-40

Zhou ZH (1996) Advances in phosphorus recycling research in agricultural ecosystem. Chin J Ecol 15(5):62-66

Zhou X (2001) Kobresia Meadow in China. Science Press, Beijing, pp 188-206 